\title{
COMPARISON OF THE POST-CAESARIAN ANALGESIC EFFECTS OF ADDING DEXMEDETOMIDINE TO PARACETAMOL AND KETOROLAC
}

\author{
Farnad Imani, Poupak Rahimzadeh, Hamid-Reza Faiz, \\ Shiva Nowruzina, Asadollah Shakeri, Mohammad Ghahremani \\ Pain Research Center, Iran University of Medical Sciences (IUMS), Tehran, IRAN
}

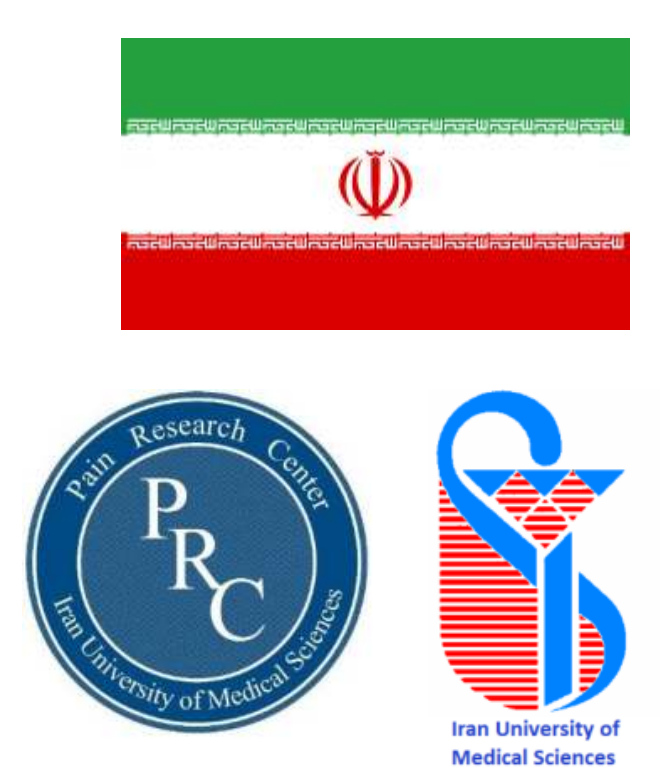

Background: Paracetamol and non-steroidal anti-inflammatory drugs (e.g. ketorolac) can be considered for mild to moderate post-caesarean pain. As a selective a-2 agonist adrenergic receptor, dexmedetomidine has analgesic and sedative effects without causing respiratory depression.

Objectives: This study aimed to evaluate the effects of adding dexmedetomidine to paracetamol or ketorolac on postcaesarean pain and the associated complications thereof.

Methods: Sixty pregnant women, who were candidates for caesarean section with spinal anesthesia, were randomly assigned to either of two groups of 30 patients. For postoperative pain management, an intravenous patient-controlled analgesia (PCA) device was used for 24 hours. Dexmedetomidine (3 $\mu \mathrm{g} \mathrm{kg}-1$ ) was added to paracetamol (35 mg $\mathrm{kg}-1)$ in the group DP and to ketorolac (1 mg kg-1) in the group DK. Visual analog scale (VAS), Ramsay sedation scale, hemodynamic changes, rescue analgesic (meperidine) consumption, patient satisfaction, and possible complications were recorded at 6, 12, and 24, hours after surgery, and compared afterward.
Results: The pain score was significantly lower in the DK group than in the DP group $(P<0.05)$. The hemodynamics and sedation scale were similar in both groups. The total meperidine consumption was higher in the DP group, but it was not significantly different. Maternal satisfaction was greater in the DK group $(P<0.05)$. Concerning complications, the two groups did not show statistically significant differences $(P=0.4)$.

Conclusions: The addition of dexmedetomidine to ketorolac, compared with its addition to paracetamol, causes further reduction in the post-operative pain score and provides more satisfaction.

Keywords: Analgesia; Caesarean Section; Dexmedetomidine; Ketorolac; Paracetamol

Clinical registry number: IRCT201601147984N24

\begin{tabular}{cccc}
\hline & $\begin{array}{c}\text { Group DP } \\
\text { (Mean } \pm \text { SD) }\end{array}$ & $\begin{array}{c}\text { Group DK } \\
\text { (Mean } \pm \text { SD) }\end{array}$ & $\begin{array}{c}\text { P- } \\
\text { value }\end{array}$ \\
\hline Age (yrs) & $29.3 \pm 5.1$ & $30.8 \pm 3.1$ & 0.6 \\
\hline Weight (kg) & $77.04 \pm 1.6$ & $76.9 \pm 11.9$ & 0.4 \\
\hline VAS at 0 hr & $61.5 \pm 12.5$ & $59.4 \pm 11.0$ & 0.1 \\
\hline $\mathbf{6}$ hr & $50.7 \pm 8.6$ & $33.6 \pm 8.9$ & $<0.05$ \\
\hline $\mathbf{1 2}$ hr & $35.7 \pm 11.6$ & $22.0 \pm 7.6$ & $<0.05$ \\
\hline $\begin{array}{c}\text { Meperidine } \\
\text { consumption } \\
\text { (mg) }\end{array}$ & $15.2 \pm 0.5$ & $12.5 \pm 1.8$ & 0.06 \\
\hline
\end{tabular}

\begin{tabular}{rccc}
\hline & $\begin{array}{c}\text { Group DP } \\
\mathbf{n}(\%)\end{array}$ & $\begin{array}{c}\text { Group DK } \\
\mathbf{n}(\%)\end{array}$ & P-value \\
\hline Very good & $3(10)$ & $21(70)$ & $<0.05$ \\
\hline Good & $19(63.3)$ & $9(30)$ & $<0.05$ \\
Moderate & $8(26.7)$ & 0 & $<0.05$ \\
\hline
\end{tabular}

Table 2. Patients' satisfaction rate. DP, dexmedetomidine and paracetamol group; DK, dexmedetomidine and ketorolac group.

Table 1.Patients characteristics, pain score, and meperidine consumption. $\mathrm{DP}$, dexmedetomidine and paracetamol group; DK, dexmedetomidine and ketorolac group; NRS, numerical rating scale. 